\title{
La representación de lo nacional en Manuela, de Eugenio Díaz Castro
}

\author{
María Ximena Hoyos Mazuera* \\ «Los cuadros de costumbres no se inventan, se copian». \\ Epígrafe de Manuela
}

\section{Resumen}

El presente artículo explora desde la literatura, las representaciones y símbolos que los sectores subalternos construyeron en la cotidianidad característica del contexto neogranadino decimonónico. Explorando por tanto la novela Manuela, del escritor nacional Eugenio Diaz Castro, la autora presenta una reflexión sobre los vestidos, costumbres, ropas, lenguajes, artes, oficios y conflictos culturales y políticos de tales sectores implícitos en la narrativa de Díaz Castro.

\section{Palabras claves}

Literatura, Sectores subalternos, Nueva Granada.

\section{Abstract}

This article explores from literature, representations and symbols that the subordinate sectors feature built into the everyday context of nineteenth-century New Granada. Exploring the novel Manuela therefore, the national writer Eugenio Diaz Castro, the author presents a reflection on his clothes, manners, clothes, languages, arts, crafts and cultural and political conflicts in those sectors involved in the narrative of Díaz Castro.

\section{Key words}

Folkloric literature, subordinates sectors, New Granada.

\section{Antecedentes}

El paisaje aparece en la narrativa americana desde el primer momento en que Cristóbal Colón pisó tierras del Nuevo Mundo. Henríquez Ureña (1994) muestra cómo el paisaje americano constituyó uno de los elementos fundamentales en la creación del imaginario literario americano y asegura que a lo largo de toda la historiografía literaria el paisaje fue un hecho esencial en la conformación de literaturas latinoamericanas, incluyendo las fundacionales, las de costumbres, las indigenistas y hasta las modernas y urbanas del siglo XX.

Debido justamente a la exuberancia del paisaje, a los difíciles accesos durante la Conquista y a las fundaciones de pueblos, la creación de medios terrestres de comunicación y de evangelización cristiana, la América Española creó un mito de "pueblo exótico" en la mirada etnocentrista de los europeos, que venían de

\footnotetext{
* Artículo tipo 2: de reflexión, según clasificación de Colciencias.

** Licenciada en Lenguas Modernas - Comunicadora Social. Magister en Literatura colombiana y latinoamericana, Universidad del Valle. Docente Pontificia Universidad Javeriana, Cali. E-mail: mxhoyos@javerianacali.edu.co
} 
conquistar otros pueblos, en Asia y África. Esa idea de animales peligrosos, ríos caudalosos, montañas inalcanzables e imperios antiguos, que se creó en la imaginación de las gentes del Viejo Mundo perdura hasta nuestros días e influenció, de manera contundente, nuestra narrativa, no sólo en la descripción del paisaje, sino también de sus gentes, sus costumbres y su cultura. En su Diario de Viaje, Colón describe de una manera muy ilustrativa sus primeras impresiones de las islas caribeñas. En extracto apuntado por el padre de Las Casas, Colón muestra "su arrobamiento ante el paisaje del Nuevo Mundo": ...es una isla muy verde y fertilísima, y no pongo duda que todo el año siembran panizo..." (Henríquez, 1994, p. 11).

La imaginación de los recién llegados los instó a escribir una serie de descripciones que en algunas ocasiones rayaban en lo absurdo, pues para los europeos del siglo XIV, las selvas americanas eran algo nunca visto, ni siquiera en los viajes que ya se habían hecho a Oriente -recordemos la Ruta de la Seda que existía entre Europa y Asia desde la Edad Media, que luego sería narrada por Marco Polo en el siglo XIII-, ni tampoco en algunos viajes expedicionarios al África mediterránea y a la sub-sahariana, como los de Livingston o Carter.

En cuanto a los viajeros europeos y norteamericanos quienes dejaron diarios y dibujos acerca de la vida en América en la primera mitad del siglo XIX, cabe mencionar que tanto las descripciones de dichos viajeros como sus dibujos de la realidad pudieron dejar una huella en la novelística hispanoamericana, aunque es difícil confirmar que los escritores locales hubiesen podido tener acceso a estos textos, ya que eran escritos en lenguas extranjeras y no fueron traducidos inmediatamente. Sin embargo, se puede afirmar que existía un espíritu de búsqueda de lo propio a lo largo del continente, y se vivía la construcción de una nueva narrativa americana que se nutría de estos elementos.

Algunos de estos viajeros llegaron por cuestiones diplomáticas o por negocios, pero la belleza de los sitios que recorrían los hizo volcar a la creación de dibujos y bocetos, en unos, y descripciones narrativas, en otros. Issac Holton, profesor de Química e Historia Natural en Middlebury College en New York, dejó consignado en su diario de Veinte meses en los Andes, buena parte de la vida y las costumbres de las gentes de la Nueva Granada, en un libro en el cual describió todo lo que vivió durante su estancia, en la primera mitad del siglo XIX:

Desde la cima tuve por primera vez una vista panorámica del valle del Cauca. Este no es completamente plano sino ondulado, como dicen en el Oeste, y el color verde vivo es maravilloso después de las llanuras secas de Ibagué y El Espinal. No creo que haya un espectáculo más hermoso que esta vista del valle del Cauca, rodeado todavía por las ásperas montañas del Quindío, mientras que en la distancia se divisan las de Caldas" (Holton, 1981, p. 395-396)

Así como hubo narradores y descriptores del Nuevo Mundo, hubo también pintores que dejaron sus dibujos y acuarelas. Uno de ellos fue Edward Walhouse 
Mark, funcionario inglés quien vino a la Nueva Granada por un asunto diplomático, y quien tenía aptitud para la acuarela, dejó un cuaderno de acuarelas en donde muestra paisajes geográficos y humanos. Este tipo de viajero, quien nació del binomio arte-ciencia, es, como anota Beatriz González, "un personaje nacido de Rousseau y del romanticismo impulsado por Humbolt, que escribe sus observaciones y dibuja a caballo o en canoa."

\section{El barroco criollo}

Durante los casi tres siglos que duró la época colonial en América hubo momentos cruciales, como la consolidación de los dos grandes virreinatos, el de México y el de Perú. La sociedad estaba dividida entre los españoles y sus descendientes y el resto de la población, que estaba constituida por las diversas razas que surgieron a partir del mestizaje entre blancos, indígenas y negros. Durante este largo y sombrío periodo de la historia de América, la narrativa no era parte importante entre la población, aunque en las esferas altas hubo grandes escritores y escritoras, que desarrollaron importantes textos de gran influencia barroca. Algunos de ellos fueron Sor Juana Inés de la Cruz, en México; Josefa del Castillo y Juan Rodríguez Freyle, en la Nueva Granada, y el Inca Gracilazo de la Vega, en el Virreinato del Perú. Octavio Paz (1950), en su ensayo El laberinto de la soledad, lo denominó el barroco criollo, por la mezcla de lo indígena y lo español. Este concepto debe ser "entendido no tanto como lo opuesto a la metrópoli, sino como la adaptación idónea de la forma barroca peninsular... en la América Hispánica..." (Figueroa, 2007). Esas metáforas exacerbadas y el encubrimiento constante de las palabras son una identidad narrativa que están presentes en la cultura mestiza latinoamericana, en sus Artes y sus Literaturas, y son el elemento constitutivo de un discurso literario muy propio y que se enriqueció con las descripciones detalladas de los escritores post-independentistas como Eugenio Díaz Castro en Colombia.

El mundo barroco, que todavía era muy fuerte en España en el momento de la Conquista, se instauró y se metamorfoseó en todas las Artes de América. Y esta mezcla dio pie a la creación de diversas expresiones populares que existen hasta nuestros días y que de un modo u otro son parte del imaginario colectivo americano y han sido influencia para la narrativa del siglo XIX y buena parte del siglo XX. Las habaneras, guajiras, cumbias, marineras o bambucos, por nombrar solo algunos ritmos musicales, que eran de las pocas manifestaciones culturales que se permitían hasta cierto punto por las autoridades eclesiásticas, se fortalecieron y dieron origen a los carnavales y a las fiestas patronales que sobrevivieron hasta nuestros días en toda América.

\section{Las expediciones científicas}

Después de la Independencia, la Comisión Corográfica, que se llevó a cabo entre 1850 y 1859, fue la expedición científica más importante que se hizo en la nueva República. El descubrimiento de las gentes y costumbres de la Nueva Granada significó un nuevo acercamiento a las diferentes razas que conformaban nuestra naciente nación. La Expedición Botánica, fundada en 1783 por Carlos III, que 
todavía era muy colonial en su estructura de investigación, se inclinaba hacia lo natural, a lo más primigenio, mientras que la Comisión Corográfica tendía más hacia el paisaje humano: lo humano como objeto de curiosidad. Si para Mutis las urgencias eran el estudio y el inventario de las riquezas naturales, y su consecuente elaboración de las láminas para construir la flora neogranadina, para Codazzi y Ancízar fueron las de observar y organizar la geografía humana, para plasmarlas en acuarelas y dibujos.

Loaiza (2004) explica la forma como se hicieron los levantamientos de los mapas de las nacientes naciones americanas durante la Comisión. "El teniente coronel Codazzi, junto con el dibujante Carmelo Fernández quien lo acompañó en el levantamiento del mapa general" (2004, p.189), con un deseo enorme de crear nación y dispuesto a sortear todas las condiciones naturales por hostiles que fueran. Los científicos y dibujantes de este proyecto no sólo hicieron la cartografía de la República de la Nueva Granada, sino que dejaron un legado artístico muy importante, representado en acuarelas, dibujos y grabados de los tipos humanos y los paisajes, de los mapas y las cartografías, de Agustín Codazzi, y los libros de viajes, como Peregrinación de Alpha, en donde quedaron consignadas las travesías agobiantes de hombres como Manuel Ancízar y sus compañeros. En general, la Comisión Corográfica tuvo como propósito el reconocimiento de los recursos naturales de Colombia, el clima, la topografía, el relieve , la geografía humana y, en especial, hacer la cartografía de todo el país.

Estas dos expediciones fueron producto no sólo del afán civilizador de las clases hegemónicas del país en momentos cuando era imperativo conocer las riquezas naturales y humanas para explotarlas comercialmente. Detrás de la intensión de la clasificación y el inventario obviamente había intereses económicos que venían de la metrópoli europea. Sin embargo, no se puede desconocer la influencia del movimiento romántico en esos proyectos colosales en varios países americanos. En cuanto al aspecto literario, los escritores románticos franceses desarrollaron varias de las características del romanticismo como el exotismo, el amor a lo propio, la inocencia en oposición a la crueldad de la realidad, descripciones de las costumbres de las provincias, lejanas a las grandes capitales, influencia que se vino a reflejar en varias novelas fundacionales como Manuela de Díaz Castro o María de Isaacs.

\section{La literatura costumbrista colombiana}

Los pintores del proyecto nacional de la Comisión Corográfica (Carmelo Fernández, Enrique Price y Manuel María Paz) dejaron constancia de las costumbres y los usos, del vestuario, de las producciones, de la naturaleza y del paisaje, con lo que dieron inicio a un movimiento artístico muy propio de Colombia: Los cuadros de costumbres. De ahí nacería el amor por lo nuestro, buscando la representación de lo que se había estado constituyendo desde el primer momento del mestizaje. Este proyecto influyó fuertemente a la literatura costumbrista al 
relacionar sus cuadros de investigación científica y la pintura detallada de las regiones y sus personajes, en el sentido de que los artículos, en su mayoría, de corte periodístico, como la crónica, el reportaje o la anécdota, fueron escritos con la intensión de describir los objetos y las personas, sin entrar a confrontar el medio social o cultural que estaba siendo descrito.

La literatura costumbrista colombiana surge a partir de una serie de descripciones de algunos escritores nacionales "no como contenido literario que ceda sus prerrogativas a la imaginación, sino como una realidad sistematizada de datos" (Luque, 1976, p. 7), y que luego se transformaría en el entusiasmo de "pintar" y "retratar" los diversos matices de la vida nacional del momento. Este hecho está íntimamente ligado a la aparición del periódico literario El Mosaico, que nace el 24 de diciembre de 1858, de un grupo de intelectuales de Santa Fé de Bogotá, entre quienes se encontraban José María Vergara y Vergara, José Manuel Marroquín, Manuel Ancízar, José Manuel Groot y el propio Eugenio Díaz Castro. La idea fundamental del periódico fue el de crear un círculo entre los literatos del país, y cómo consta en el núm. 1, del 24 de diciembre de 1858, el periódico se proponía "hacer conocer el suelo donde recibimos la vida, i donde seguirán viviendo nuestros hijos. A nosotros nos toca el elojio de las grandes acciones, la pintura de nuestros usos y costumbres". (Loaiza, 2004). Otro objetivo de la publicación literaria se basaba en "darles coherencia a las dispersas individualidades del momento" (1976, p.3) de los diversos escritores de la época y que dio inicio al Museo de cuadros de costumbres, en donde se consignaron la crónica urbana, los versos jocosos, las novelas por entregas, las listas de novedades bibliográficas, las biografías de hombres ilustres y algunos relatos costumbristas lo que se convertiría luego el Museo de cuadros y costumbres.

Antonio Curcio Altamar, en su obra Evolución de la novela en Colombia, que estudió la novela desde la Colonia hasta 1924, año en que se escribió La vorágine, de José Eustasio Rivera, incluye al Costumbrismo en el capítulo del siglo XIX y lo tipifica como una corriente literaria que se caracterizó por retratar e interpretar las costumbres y tipos del país. Es la descripción casi fotográfica de las costumbres de un individuo, de una familia o de una región. Al pintar las costumbres, se resalta más lo ridículo, para satirizar, hacer la burla, moralizar o dejar a la posteridad las características simpáticas de las costumbres de una época. Señala, además, que algunas de las características más importantes de Los cuadros de costumbres son el localismo, en sus tipos y lengua; el color local, énfasis en el enfoque de lo pintoresco y representativo, muy propio del Romanticismo; popularismo; sátira y crítica social, con intención de reforma; infiltración del tema político-social; reproducción muy detallada de la realidad con escenas a veces muy crudas y vocabulario rudo y hasta grosero. Algunas de estas características están plasmadas en Manuela, novela de Eugenio Díaz Castro, publicada en 1858.

\section{Las voces subalternas}


Según Cristina Rojas (2001), en su texto Civilización y violencia: la búsqueda de la identidad del siglo XIX, los subalternos, es decir, todos aquellos ubicados en los rangos más bajos de la civilización, los indios, los negros, los artesanos y campesinos y las mujeres, tenían un punto de vista y una voz por medio de la que impugnaban su monológica representación del mundo y, en este caso, de la naciente Nación. Como la historia se escribe desde el punto de vista del que ostenta el poder, y vemos claramente que, en el caso de Colombia en el siglo XIX, la historia era narrada desde este punto de vista: "hombre blanco, rico, católico y poderoso" (2001, p. 150-151), nos valemos de la literatura para encontrar esas otras voces, que están escondidas debajo del discurso predominante. Recuperar esas voces subalternas requiere analizar los discursos y plantear una relación dialógica entre el autor y el contexto. Es decir, el mundo representado no reproduce el mundo real y los autores son también sujetos culturales, que no son totalmente libres para construir sus propias visiones. "Una forma de reconocer al Otro es ver a través de los ojos del otro, puesto que el modo en que uno se define a sí mismo no es independiente de la mirada del otro. Quien se siente y se denomina a sí mismo civilizado inmediatamente le está dando el matiz de bárbaro al otro" (2001, p. 150-151).

Mújica (1985) comenta que en Colombia fue Eugenio Díaz Castro quien inauguró la novela de costumbres utilizando un "realismo pasmoso" (1985: 3), descrito en su Manuela (1858), y que fue "el primer escritor que describe la resistencia frente a las condiciones de trabajo impuestas en las haciendas paneleras de Sumapaz", de acuerdo con la misión civilizadora predominante. Manuela es una mujer mestiza y pobre que representa a la vez un punto de resistencia y un objeto de deseo. El hecho de que Díaz escogiera a una mujer, y además morena, como Manuela, y que la exponga como su heroína, lo enmarca en el movimiento romántico en su afán por describir la gente del pueblo y contar las condiciones en las que malviven.

Según Baldomero Sanín Cano, Manuela no es solamente un cuadro realista en donde se desempeñan los tipos raciales de una región de Colombia, como siempre se la ha catalogado equivocadamente, o la descripción detallada de los diversos aspectos de la naturaleza, sino que también "se hace presente el desequilibrio social resultante de la desigualdad social en que vivían los trabajadores del campo" (1984, p. 5). En Manuela vemos la pugna política de liberales y conservadores, la dura vida del campo, sobre todo de los campesinos sin tierra, que tienen que trabajar en condiciones infrahumanas, y también, la cultura popular colombiana de mediados del siglo XIX en Colombia.

Sin embargo, la novela tuvo muchas críticas por parte de los eruditos del momento, que decían que estaba escrita por un hombre poco académico y que tenía fallas de la estructura gramatical española. Empezó a circular con el primer número de El Mosaico, en 1858, pero su publicación fue suspendida en el capítulo VIII, porque, según Vergara, "don Eugenio no quería poner en limpio los confusos borradores". En 1866, Manuela apareció como parte de la colección Museo de cuadros de costumbres, dirigida por Vergara, y sólo hasta 1889 fue publicada en 
una edición independiente, por la Librería Española, de Garnier Hermanos, en París (Cuarenta y seis años después de la Independencia).

Elisa Mújica (1985) revela la razón por la cual Manuela no obtuvo la importancia que merecía a pesar de sus "aciertos psicológicos, extraordinaria riqueza ambiental y lexicográfica, esclarecedora de dolorosos y significativos episodios de la vida nacional" (1985, p. 3-4). José María Vergara y Vergara, Carrasquilla y Marroquín corrigieron los manuscritos que les hacía llegar el señor Eugenio cada mes para publicarla por entregas en El Mosaico. Este hecho ha demeritado a su autor como escritor erudito. Esta es una novela que siempre ha sido menospreciada en el ámbito académico nacional, desvirtuando su sencillez y el naturalismo de su escritura.

Don Eugenio era un gran conocedor de la vida en el campo y de las formas de vivir y de hablar de la gente trabajadora. Su exactitud y veracidad, su ingenio y sensibilidad para describir en el mundo rural, especialmente de la tierra caliente, le dio la capacidad para describir interesantes y poéticos personajes, objetos y costumbres de la zona caliente del Magdalena. El mismo fue capataz de varias fincas y vivió gran parte de su vida rodeado de estas gentes. Su habilidad para "retratar la realidad" no la aprendió en ninguna escuela ni universidad, fue autodidacta y siempre escribió en su escritorio, que lo acompañó toda su vida, y con diversas clases de plumas, de pato, ganso, etc., se dedicaba en sus horas de descanso a redactar sus vivencias. Por esto, sus obras están impregnadas de color local, de escenas realistas, de humor, de descripciones detalladas de los sitios que él conocía como la palma de su mano, de caracterizaciones de las campesinas frescas e ingenuas, pero también, de carácter fuerte, como es el caso de la protagonista-heroína en Manuela.

\section{Espacio geográfico de Manuela}

Don Demóstenes Bermúdez llega a una población de clima cálido que dista un día de viaje de Bogotá, en las estribaciones de la cordillera oriental, hacia el río Magdalena, cuyas tierras se dedican principalmente al cultivo y beneficio de la caña de azúcar (panela, mieles y guarapo) y fundada, según la novela, hacia 1750. Este pueblo no aparece con su nombre propio, sino aludido como "la parroquia". Luque (1986, p. 12) y otros han identificado en él la población cundinamarquesa de Mesitas del Colegio, en la antigua provincia del Tequendama, bañada, como "la parroquia, por las aguas incontaminadas (en aquel tiempo) del río Funza o Bogotá". Por cortos espacios la trama se traslada a la sabana de Bogotá y a otro pueblo, Ambalema, localizado en el valle del Magdalena, famoso en aquella época como centro de la explotación y exportación del tabaco, a dos días de viaje desde la parroquia, por los caminos de entonces. Se mencionan otros pueblos, como Guaduas, por su presidio, y Cáqueza, por sus trapiches, y el camino utilizado para ir de Sogamoso a la región de Antioquia por el nevado del Ruiz. 


\section{Las representaciones de la vida nacional colombiana en Manuela de Eugenio Díaz Castro}

La idea fundamental de este artículo es mostrar, por medio de algunas descripciones en la novela Manuela, de Eugenio Díaz Castro, las personas, los hechos, las costumbres y las actividades sociales que solían hacer los neogranadinos que pertenecían a la clase trabajadora y cómo esos sujetos y actividades representaban estos episodios nacionales en la recién creada nación que hoy se conoce como Colombia. Además, partiendo de estas descripciones, mostrar cómo esas voces subalternas (Rojas, 2001, p. 150), en una sociedad tan cerrada y pacata como la Colombia decimonónica, logran tener voz a través de la literatura, en este caso, en el texto de Díaz.

También se intenta hacer una analogía entre esas narraciones descriptivas de Díaz Castro y algunas de las acuarelas, dibujos y/o grabados que muchos viajeros e intelectuales de la época hicieron de la entonces República de la Nueva Granada: Ramón Torres Méndez, Carmelo Fernández y Henry Price, entre otros, para visibilizar las otras razas mestizas que existen en nuestro país, y comentar acerca de sus formas de vida y de trabajo, de sus representaciones culturales y de su riqueza lingüística y su creatividad artesanal.

\section{El vestuario}

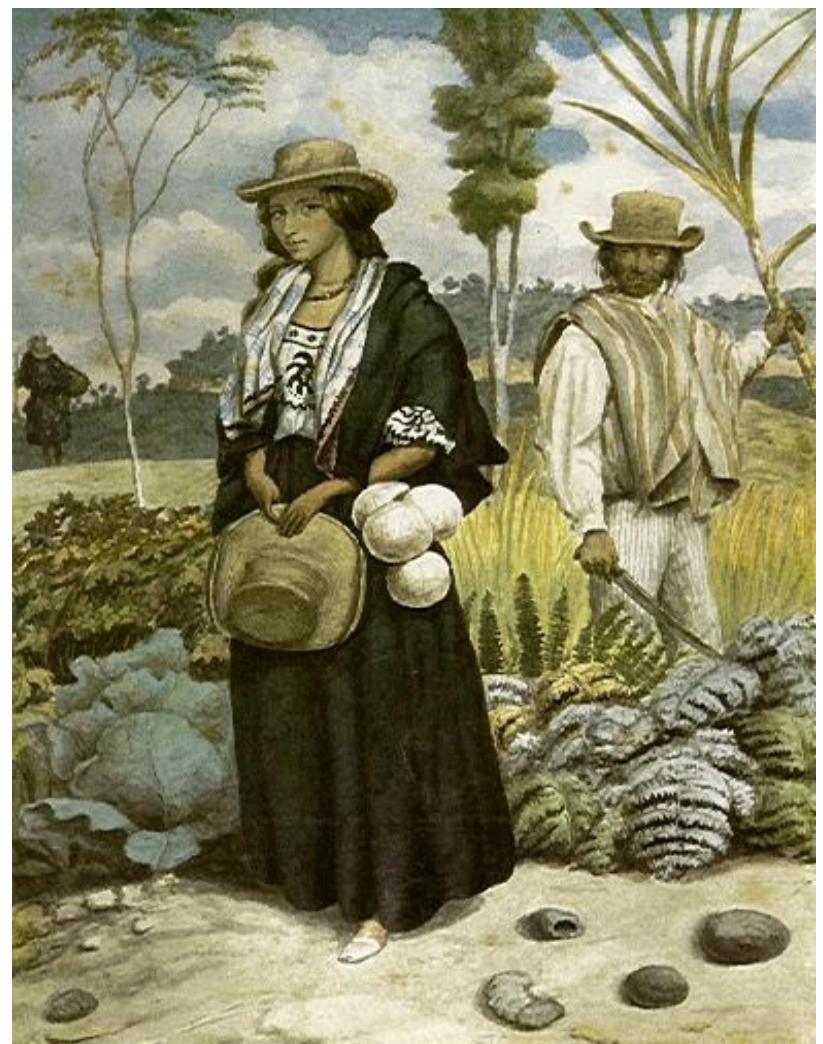


Acuarela de Carmelo Fernández, 1851 (Primera Expedición).

"El traje general de las peonas era de bayeta de frisa azul y de sombreros de trenza de palma, pero había algunas de mantilla de Castilla y sombreros finos de los que usan los estancieros del Magdalena" (Díaz, p. 140).

La descripción del vestido no sólo comunica una forma del vestir de la época y la clase social de los personajes, sino que también le da un "tono" de nacionalismo, muy propio de los románticos en su afán por describir lo autóctono como lo nacional. El vestido hace parte de una intrincada red de convencionalismos sociales que denotan no sólo una época, sino una forma de pensamiento y un sentir del momento. Es uno de los elementos estructurales de una narración, porque denota parte de la caracterización de los personajes. En Manuela hay una dedicación por describir con detalle cada una de las prendas que lleva el personaje, para acercarnos a su oficio y personalidad por lo que lleva puesto. Al personaje principal la conocemos por las descripciones detalladas en su forma de vestir de campesina, como "Marta...su traje era el mismo de su prima Manuela: camisa bordada, enaguas de cintura y pie descalzo..." (Capítulo XI), por el contrario, Cleotilde, que es una mujer de la clase alta por su "traje que bajaba hasta el suelo, dejando ver al través de un velillo celeste un color bellísimo de mármol y unos ojos grandes, suaves y modestos, una dentadura fina y graciosa, conjunto de primores, visión enteramente milagrosa, era la divinidad que había posado delante de la puerta". (Díaz, cap II)

\section{Lenguaje del pueblo y reyertas en la calle entre trabajadores(as)}

- Mire, ñuá Sinforiana, que no sea pendenciera.

- ¿Con que me amenazas? Perra atrevida. ¿Quieres ver cómo te compongo el bulto?

Diciendo esto, se acercó la vendedora de la calle del Caucho a donde estaba Ascensión, y tomando la ropa de Don Demóstenes en las manos, rasgó y dispersó varias piezas, y empujando el lavadero con una pequeña palanca, lo botó al fondo del charco... (p. 171).

Díaz maneja con maestría el lenguaje del pueblo. Conoce sus palabras, sus significados, sus formas de interactuar, debido a que él mismo fue durante varios años capataz en las haciendas paneleras. Él conoce muy bien los dichos y refranes del pueblo, que básicamente son parte de los diálogos que mantienen sus personajes y, además, su impronta como escritor costumbrista. Aprovecha el 
manejo de la lengua vernácula para escribir y hacer humor, y del fino, para situarlo en la caracterización de los personajes que aborda.

Describe con picardía de periodista y con precisión de etnógrafo sencillas situaciones que pasan en la vida de la parroquia, como cuando a la "marrana grande" se le soltó la horqueta legal y Manuela no la pudo enlazar y armó un safarrancho por todo el pueblo, en el que los dos bandos políticos se enfrentaron y terminaron en una pelea de padre y señor mío. El autor pone en boca de sus personajes palabras y dichos muy propios del campo, como chiribicos, hamacas, guarapo, barbacoas, contra-fómeque, etc., o palabras mal pronunciadas como "el gubernamiento", "carne de aújas", "aínas me lo rebajan" siempre en contraposición al lenguaje del viajero que tiene educación formal en el exterior. Utiliza expresiones del dialecto tolimense, como por ejemplo: "Espere un poquito su persona" (p. 244), con la idea de mostrar la forma como hablan en su región.

\section{El paisaje como elemento evocador}

Caminaron todo el día y a las cinco y media aparecieron a la vista de Manuela los tejados de la famosa ciudad de Ambalema. Parecían que habían quedado encendidos con los ardores del sol, y Manuela se condolió de una población que no gozaba como su parroquia de la vista de tres o cuatro aldeas, porque no había meditado que por la margen de Ambalema pasaban las gentes de cien pueblos, y que las colinas pintorescas estaban aquí compensadas con las canoas, los champanes y las balsas... (p. 239).

El paisaje se describe también con la intensión de retratar las realidades que viven los personajes. Este es uno de los elementos claros del costumbrismo, que después alimentaría al realismo. La "naturaleza poetizada" es el rasgo narrativo más sobresaliente, además de ser un rasgo profundamente romántico.

La naturaleza maravillosa subyace a lo largo de toda la novela. Pareciera que en Manuela la trama estuviera incompleta y que Don Eugenio la incluyó como una excusa para describir el paisaje, los tipos y las costumbres de los campesinos, mujeres, indígenas y mujeres de la Nueva Granada en sus primeros años como República, es decir, el autor crea un escenario natural en donde enmarca a sus personajes, que se mueven, viven, comen, trabajan, cazan, pelean y bailan en una escenografía natural que va acompañada de diálogos reales de esas gentes. Las plantas, flores, pájaros, mariposas y demás animales de la selva americana son vistos como el paraíso, el edén americano, que podría perderse por las injusticias sociales y las innumerables guerras que padece el país. Esa premura por describirlo todo indica también un miedo de perderlo: bajo el relato descriptivo del escenario pastoril y bucólico se esconde el miedo a perder el paraíso. Es así como el placer que proporcionan los lugares intactos y la (presumible) inocencia de los habitantes del mundo rural se observa en el más importante ejemplo de la literatura de Cuadros de costumbres colombiana. Díaz fue uno de esos grandes observadores del paisaje que le rodeaba y al mismo tiempo el paisaje era ese "ente divino" que lograba inspirarlo. 


\section{Las razas presentes en el país}

Manuela es la primera novela colombiana que muestra casi todas las razas existentes en el país, aunque algunas de ellas sólo están mencionadas o descritas someramente, este hecho se hace importante en un estudio de la historiografía de la literatura colombiana.

Los asientos eran taburetes y escaños. Las señoras eran cincuenta o sesenta peonas de los aliños, todas de traje blanco, y todas muy bien surtidas de oro. Los rostros eran morenos en la generalidad, siendo matizada la mayoría por una minoría de una que otra blanca de Bogotá, de Ibagué... Es notable cómo se han cruzado las razas de estos pueblos. Ya no se veía sino uno que otro tipo de las tres razas madres, la blanca, la indígena y la africana. Había hijas de Llano-grande muy agraciadas, indias de San Luis y de Coyaima, y morenas de Ambalema y sus cercanías" ( $p$. 268).

La parroquia es un lugar típico del territorio nacional, tanto por su geografía como por la riqueza de su fauna, su flora y por los aspectos sociales, políticos y económicos. Allí se dan cita personas de todas las clases sociales, de todas las razas y de todas las creencias políticas. Hay varias mujeres y de distintas razas. De las blancas están Juanita, Cecilia, Marta, Cleotilde, etc. La descripción se detiene en los tipos humanos: las peonas de tierra fría, Dolores Gacha, de raza indígena, y Francisca Rubiano, de raza blanca, pero de padres empobrecidos, tímidos y recatados, contrastan con la desenvoltura de Manuela y otras "calentanas". El propósito de estos contrastes es, en primer término, resaltar el choque entre "la alta cultura", inmersa en la tradición letrada, ilustrada y erudita, que actúa como "supercultura", y la popular, de naturaleza oral y muy cercana a lo vital, local y provinciano, que podría definirse como "subcultura", y, en segundo lugar, la rica diversidad de culturas que comporta el territorio nacional y que están en contacto unas con otras en lo que podría llamarse un proceso de interculturación.

La figura de la estanciera fue muy sobresaliente en el siglo XIX, pues se trata de una mujer del campo que se ve enfrentada a diversas situaciones, porque generalmente atiende una tienda y da posada a los forasteros, además de las múltiples obligaciones de su propia familia. Manuela es una de ellas. Y por eso es natural que ella sea una líder popular en la parroquia. Mientras que un personaje femenino como el de Cleotilde, hija de Don Blas, el dueño de la Hacienda en donde está el trapiche, es un personaje con menos fuerza que no logra desarrollarse mucho.

5. Los bailes y

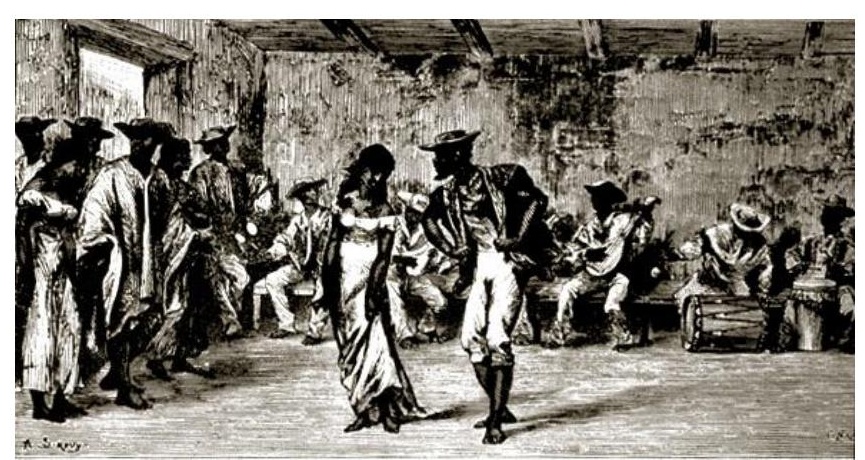

danzas 
Baile del bambuco en El Bordo, grabado de G. Barbant, 1869.

“...era el torbellino, en que el galán da vueltas en pos de la esquiva pareja, repitiéndose una parte, con la ejecución de cada cuatro de estas vueltas... esto es muy colonial sobre todo" (p. 22).

El personaje masculino observa y da su punto de vista acerca de las diferentes prácticas culturales campesinas de las regiones de Cundinamarca y el Tolima grande. Para don Demóstenes, el baile del torbellino es muy retrógrado y lo compara con los valses europeos a los que él está acostumbrado. Y quiere enseñarle a Manuela cómo bailar ese vals europeo, pero ella no quiere, porque lo encuentra aburrido y extranjerizante y prefiere el torbellino. Sin embargo, su madre, Patrocinio, la regaña por dárselas de muy colombiana, cuando le dice: "Malhaya la chiquita, que le pueden ojear..." (p. 98).

Una de las descripciones más importantes que se debe resaltar es el de las fiestas de San Pedro y San Juan en Ambalema, cerca de las aguas del Magdalena. Estos Cuadros de costumbres de Manuela son unos de los documentos históricos más importantes en una novela colombiana de esa época, pues no se tiene conocimiento de que otra novela colombiana haya descrito cómo se bailaba el bambuco y/o el torbellino en la zona del Tolima y además incluye los versos de varios cantos que son parte del folclor de esa región.

\section{Artes y oficios de los neogranadinos}

- ¿Y en qué buscas tu vida, Rosa?

- En la labranza, cuando se puede trabajar, y la mayor parte del año en el trapiche de la hacienda.

- ¿Eres trapichera?

- Sí, señor: de la Soledad, del trapiche de mi amo Blas, nada menos (p. 7).

Las actividades laborales se van entremezclando con los personajes, que van apareciendo como parte de la atmósfera, en una búsqueda etnográfica de los elementos culturales que son parte del paisaje de la obra. Es muy propio de los científicos decimonónicos instalar el personaje en su ambiente natural y dentro de la vida, que es vista por el autor desde su mirada de explorador. Don Demóstenes siempre está en el límite de una barrera cultural de clase alta y baja desde la que observa lo que pasa frente a sus ojos. La lucha constante entre la civilización y la 
barbarie se prefigura a lo largo de la novela, como en el Facundo, de Sarmiento; la novela negra cubana y la novela indigenista peruana.

En Manuela encontramos todo tipo de trabajador del pueblo y la manera como es explotado. Está el baquiano; el arriero, ñor Elias; el cazador, Don Dimas; Manuela, la lavandera; Pía, la guardiana; Doña Patrocinio, la casera; La Lámina es la estanciera; peonas, como Matea o Rufina; José Fitatá, indio puro, criado de Don Demóstenes. Están también los de las clases altas, como Don Blas, dueño del Trapiche; Don Tadeo, que es de clase popular, pero adquirió poder político como el abogado tinterillo, figura legendaria colombiana. Una buena descripción de uno de los personajes inmediatamente remite a la caracterización y al mismo tiempo, a épocas remotas de la historia colombiana:

El baquiano era ñor Elías, famoso cazador de osos y cafuches, quien conocía todos los montes como las palmas de sus manos. El traje de éste era un pantalón muy raído; en lugar de camisa tenía una camiseta pequeña, un sombrero redondo que casi ni ala mostraba, y unos zamarros que apenas bajaban a la rodilla. Al costado le colgaba un carriel mugriento, que él llamaba chuspa, en el cual cargaba tabaco y el recado de candela, agujas y una navaja pequeña(Díaz, Cap.VII)

\section{Prácticas culturales campesinas (folklore)}

El canto era de una peona de Llano-grande que hacía un primo sin igual y de un peón de Ambalema que le hacía un segundo, acompañándose con el tiple. El canto era fluido, libre y sonoro y lo favorecía el temple de la atmósfera de media noche y el eco de los grandes edificios... Las armonías que tiene el bambuco en sus mudanzas conmovían sucesivamente todos los sentimientos de Manuela... (p. 270).

El afán civilizador propio de los criollos en el siglo XIX, dio por comparar las prácticas culturales de las personas de las clases hegemónicas con las de las clases subalternas. Los escritores costumbristas se dieron a la tarea de mostrar esas costumbres de las clases subalternas, describiéndolas y dándoles un sitio en la narrativa de sus poemas, cuentos y novelas. Díaz le dio mucha importancia a comentar estas prácticas y las describió con buen humor en casi todos los cuadros de costumbres. En Manuela se describe cómo dos peones tocan y cantan un bambuco, acompañados de un tiple; la forma como bailan el Sanjuanero, cuando se van a Ambalema; los trajes que usa cada trabajador del campo; sus mercados campesinos en la parroquia, y las chozas en que malviven en la rivera del Magdalena.

El discurso popular y marginal de la protagonista y de los otros personajes de la parroquia va contra la narrativa conservadora y hegemónica de las élites, representadas por don Demóstenes, es en cierto modo, un discurso literario que se presenta como una contrahegemonía en el proyecto nacional de la consolidación de un estado-nación a mediados del siglo XIX. Según Sergio 
Escobar en su artículo "Manuela, de Eugenio Díaz Castro, o la novela sobre el impasse de fundación nacional", el discurso narrativo de la obra "es un espacio discursivo permeable a las narrativas alternativas y contrarias a la de la modernidad colonial". (Escobar, 2006) y utiliza a un personaje como don Demóstenes para "emprender un estudio de estas narrativas" desplazándolo desde la capital del país a un pueblito localizado en las vecindades de la sabana bogotana".

En la novela, don Demóstenes ha aprovechado su estadía para ir al campo y se ha dedicado a coleccionar pájaros y plantas para hacer un herbario, pero todo lo ha dejado encima de las mesas. Cuando vuelve, después de dar un paseo, se da cuenta de que Manuela le ha guardado y limpiado todas las clasificaciones que tenía separadas para hacer su investigación y que le habían costado tantos días de trabajo. Ella simplemente le contestó que estaba limpiando "el cuarto que parecía de locos". Esta escena muestra claramente la lucha constante que se vivía en la Colombia decimonónica entre la civilización y la barbarie. Don Demóstenes representa el sujeto civilizado, educado fuera del país, mientras que Manuela es una campesina que no sabe nada. Ella misma es un objeto de estudio para un naturalista como el señorito de la capital. Él es un hombre que sabe leer y tiene acceso a la prensa escrita colombiana de aquella época: "Don Demóstenes se puso a leer «El Tiempo» y el "Neo-granadino...” (Díaz, Cap. XI).

Otro ejemplo que muestra esta lucha constante es cuando el autor cuenta cómo los peones, después de que les pagan, se van a gastárselo en la estancia de ñuá Sinforiana para "... comprar chica y aguardiente, jugar al turmequé, al tangano y a la baraja, tocar tiples, hablar insolencias y cantarles a las muchachas..." (p. 207), sin pensar en que deben dedicarlo a la comida de sus familias.

\section{Situaciones peligrosas}




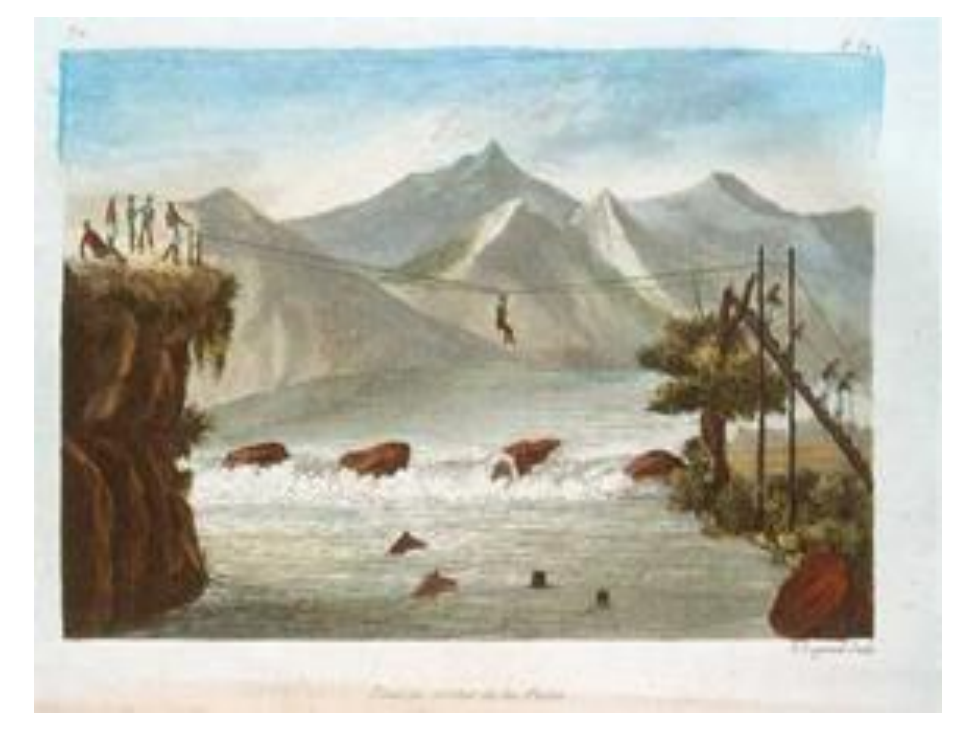

\section{Viajes ilustrados por Colombia, 1817-1857, Georgio Antei.}

Pero no habrían caminado media cuadra, cuando ñor Elías, que se ha adelantado, dio un lastimoso grito diciendo:

- ¡Socorro! ¡Socorro!

- ¿Qué hay? -le preguntó don Demóstenes corriendo a donde se halla Elías, a quien halló colgado de un pie.

- Que mi compañero Limas sabe más que yo, porque me ha cogido una de sus trampas. Me tiene colgado de una pata nada menos... corte su merced esta soga o bejuco con su cuchillo; pero no le hace, que arrieros somos y en el camino nos toparemos (Díaz, Cap. VII).

En una expedición a la montaña, Don Demóstenes va acompañado de ñor Elías, el baquiano, y aprovecha para comentar la forma en que vivían aquellos hombres y mujeres, cómo cazaban y cuáles eran sus supersticiones: descripción tan minuciosa es el deleite de todo investigador cultural que se dedique a estudios histórico-geográficos en la narrativa del diecinueve. No sólo la caza se tornaba una situación peligrosa, sino que cada viaje por el Magdalena, por el Darién o por cualquier zona del Chocó era toda una aventura. Y los escritores decimonónicos no perdieron oportunidad de describir estos viajes. Díaz, como conocedor de su tierra y de su gente, aprovechó para narrar con gran detalle y expresión, las dificultades que acarreaban los viajes por estas tierras vírgenes y poco exploradas, en algunas ocasiones en un tono y ritmo parecido al de los diarios de muchos viajeros europeos que recorrieron nuestra geografía en el siglo XIX, como lo cuenta Ernst Röthlisberger en su diario "El dorado", en 1881: "Ahora el camino empieza a ascender en cerrado zig-zag. Piedras redondas dificultan el andar de las mulas, la silla se desliza hacia atrás con la violenta subida..." (Röthlisberger,1993, p. 65)

Casi todos estos viajeros extranjeros que vinieron a Colombia en el siglo XIX describen algún accidente que sufrieron cuando visitaron el país. De alguna forma u otra, vivieron penalidades ya sea por la travesía del río Magdalena, recorrido de las trochas para llegar a Bogotá o bajar hasta el Valle del Cauca atravesando la 
selva del Quindío. Díaz Castro también dejó consignado en sus novelas y en sus cuentos, descripciones sobre lo peligroso que podía ser ir de un lugar a otro dentro del territorio nacional.

\section{La gastronomía}

¿Y qué hay del cafecito? le preguntó el viajero.

— ¿Cuál cafecito? -le contestó ella con la más franca admiración.

- El de mi cena.

- ¿Luego usted cena?

- Por de contado.

- ¿Trajo de qué hacerle? ¿Tiene algo en esos baúles?

- Sí: los libros y la ropa.

- ¿Eso merienda, pues?

- No, lo que tú me prepares.

- ¿Y si no hay nada?

- ¿Cómo?

- Que en estos caminos hay que llevar de comer, porque no se encuentran las cosas al gusto de los pasajeros.

— ¡Yo no acostumbro cargar nada de comida, mi hija!

- Pues entonces, aguante (Díaz, p. 6).

Como muchos de los cuadros de los viajeros que vinieron a la Nueva Granada en el siglo XIX, el tema de la comida se describe más o menos de la misma forma. Que no hay mucho para comer o que hay que esperar para comer algo bueno. Isaac Holton cuenta que, después de viajar varios días, llegaba a una hacienda y no encontraba más que una taza de chocolate y una arepa reseca. En varias oportunidades a Don Demóstenes le pasa lo mismo. El mismo Manuel Ancízar lo relata en su Peregrinación de Alpha, cuando habla de "la sencillez de su gusto gastronómico", refiriéndose a los distintos platos que probó durante su viaje por los alrededores de Zipaquirá y Chiquinquirá.

El primer día en la Posada del Mal Abrigo, Rosa no tiene nada para ofrecerle a nuestro personaje, Don Demóstenes, como lo sufrirán los viajeros europeos y norteamericanos que vinieron a la Nueva Granada en el siglo XIX. Lo relatan tanto el norteamericano Isaac Holton, el inglés John Potter Hamilton y el francés JeanBaptiste Boussingault, a pesar de que América era la despensa agrícola de Europa y que tenía gran variedad de frutos, verduras y plantas.

\section{Los descalzos y los embotados}

¿Y por qué los dueños de tierras nos mandan como a sus criados? ¿Y por qué los de botas dominan a los descalzos? ¿Y por qué un estanciero no puede demandar a los dueños de tierras? ¿Y por qué no amarran a los de botas que viven en la cabecera del cantón, para reclutas, como me amarraron a yo en una ocasión, y como amarraron a mi hijo y se lo llevaron? ¿Y por qué los que saben leer y escribir, y entienden de las leyendas han de tener más priminencias que los que no sabemos? ¿Y por qué los ricos se salen con lo que quieren, hasta con los delitos a veces y a los pobres nos 
meten a la cárcel por una majadería? ¿Y por qué los blancos le dicen a un novio que no iguala con la hija, cuando es indio o negro? (p. 140).

A lo largo de la novela hay una pugna constante entre las clases hegemónicas y las clases subalternas representadas por los hacendados dueños de los trapiches y los peones o trabajadores del trapiche Nuestra Señora de la Soledad. Sin embargo, entre los ricos hay algunos personajes que son buenos con los pobres, es el caso de don Demóstenes, que es gólgota o liberal radical, es el viajero que, a pesar de ser de la clase alta de la capital, siente compasión por los trabajadores y ayuda a Manuela a escaparse de su verdugo. Entre los pobres también hay otro personaje que quiere doblegar a los pobres y es representado aquí como don Tadeo. Los tadeístas están contra los ricos, los ilustrados y contra el cura, y quieren matar a Cecilia, su mujer, y persigue a Manuela y a su novio, Dámaso. Manuela es la heroína pobre y tiene sus seguidores. Los manuelistas simpatizan con los hacendados humanitarios, como don Demóstenes y don Blas, el dueño del trapiche y padre de Cleotilde.

En el Capítulo XIII, Ilamado la Revolución, el autor juega con esta palabra utilizando la parodia de la escapada de la marrana de Manuela, que se había quedado sin horqueta, y creó un caos en el pueblo, con el fin de expresar su sentir político y de los abusos contra los pobres de los que ostentan el poder en el pueblo, en el caso de Don Tadeo que es llamado aquí como el judío que impuso esa ley de las horquetas:

- ¿Conque la revolución ha sido aquí?

-Sí, señor, en la calle del Caucho; pero eso daba miedo.

- ¿Y por qué se comenzó?

Por la marrana, señor, por la ley de la horqueta y para eso que usted mismo fue el que publicó esa ley.

-¡Pícaros!

-Y ya le digo que su criado y su perro están en la cárcel. (Díaz, Cap.XIII)

\section{A manera de conclusión}

Los subalternos no son voces receptoras pasivas, como partícipes en el diálogo, colaboran e incluso plantean resistencia a ciertas acciones. Indios, artesanos, mujeres y negros tenían una voz y un punto de vista desde el cual impugnaban una representación ideológica del mundo en la Nueva Granada del siglo XIX. La historia siempre se cuenta desde el poder, desde el hombre blanco, en contraposición a las historias de los campesinos, de las comunidades indígenas y las de las mujeres, que se consideran "sin historia", porque representan lo primitivo, lo atrasado. Afortunadamente, la literatura es un lugar desde donde se recuperan esas voces que parecen estar calladas, ya que muchas veces los escritores les dan voz a esos otros que no pertenecen al poder. Cross, en su texto El sujeto cultural (Cros, 2003), muestra que el escritor también es un sujeto cultural y tiene una voz interna que inconscientemente despliega en su narrativa. Por esto vemos que en Manuela los y las trabajadoras del trapiche tienen voces 
propias y opinan de diversas maneras, ya sea desde la descripción que el autor hace de su vestimenta y de su quehacer diario, como el arriero, como la forma de vida de una estanciera que se hace amante de un hombre poderoso y puede llegar a ser un personaje que tiene voz a través de una anécdota narrada desde otra mujer (Juanita). La defensa del campo y de las prácticas campesinas se enuncian cuando el narrador utiliza el lenguaje coloquial que se despliega a lo largo de la narración y, sobre todo, en el hecho de que la protagonista sea una mujer pobre y morena, que manifiesta el sentir del pueblo por medio de su voz femenina.

\section{Fuentes documentales}

André, E. (1984). América pintoresca. Bogotá: El Ancora editores

Díaz Castro, E. (1986). Manuela. Medellín: Editorial Bedout.

Díaz Castro, E. (1985), Novelas y Cuadros de Costumbres. Tomo 1. Bogotá: Nueva Biblioteca Colombiana de Cultura.

Holton, Isaac. (1981). La Nueva Granada: Veinte meses en los Andes. Bogotá: Banco de la República.

Röthlisberger, E. (1993). El dorado (1897). Bogotá: Biblioteca V Centenario Colcultura Viajeros por Colombia.

\section{Bibliografía}

Anderson Imbert, E. (1954). Historia de la literatura hispanoamericana. México.

Camacho Roldán, S. (1976), "Manuela", en Escritos sobre economía y política, Bogotá: Colcultura.

Curcio Altamar, A. (1975). Evolución de la novela en Colombia. Bogotá: Biblioteca Básica Colombiana, Colcultura.

Colmenares, G. (2008). Partidos políticos y clases sociales. Medellín: Editorial La carreta histórica.

Cros, E. (2003). El sujeto cultural. Medellín: Universidad EAFIT.

Escobar, S. (2006). Manuela, de Eugenio Díaz Castro, o la novela sobre el impasse de fundación nacional. Medellin: Universidad de Antioquia. En:http://www.accessmylibrary.com/coms2/summary_028632164713_ITM 
Figueroa Sánchez, C. R. (2008). Barroco y neobarroco en la narrativa hispanoamericana: Cartografías literarias de la segunda mitad del siglo $X X$, Colombia: Editorial Universidad de Antioquia y Javeriana, Colombia.

Giraldo, L. M. (2005). Cuentos y relatos de la literatura colombiana. Bogotá: FCE.

Gómez Valderrama, P. (1985). Don Eugenio Díaz Castro. Bogotá: Círculo de Lectores.

Hernández De Alba, G. (1984). En busca de un país: la comisión Corográfica, Bogotá: Carlos Valencia Editores.

Henríquez Ureña, P. (1994). Las Corrientes Literarias en la América Hispánica, Bogotá: Biblioteca Americana, F.C.E.

Loaiza Cano, G. (2004). "El Mosaico", en Boletín Cultural y Bibliográfico, No. 67. Bogotá: Banco de la República.

Loaiza Cano, G. (2004a). Manuel Ancízar y su época: Biografía de un político hispanoamericano del siglo XIX. Medellín: Universidad de Antioquia.

Luque Muñoz, H. (1976). Narradores colombianos del siglo XIX: Introducción. Bogotá: Biblioteca Básica Colombiana, ICC.

Maya, R. (1969). Cuadros de costumbres. Cali: Carvajal y Cía.

Mujica, E. (1985). Novelas y Cuadros de Costumbres. Tomo I. Bogotá: Nueva Biblioteca Colombiana de Cultura.

Peña Gutiérrez, I. (1987). Manual de Literatura Latinoamericana. Educar.

Pérez Mejía, Á. (2002). La geografía de los tiempos difíciles: escritura de viajes a Sur América durante los procesos de independencia, 1780-1849. Medellín: Editorial Universidad de Antioquia.

Reyes, C. J. (1988). El costumbrismo en Colombia, Manual de literatura colombiana. Tomo I. Bogotá: PROCULTURA, Planeta, Bogotá.

Rojas, C. (2001). Civilización y violencia: la búsqueda de la identidad del siglo XIX, Bogotá: Editorial Norma.

Sanín Cano, B. (1984). Letras Colombianas. Medellín: Colección de autores antioqueños.

Fecha de recepción: 20 de mayo de 2009

Fecha de aprobación: 21 de septiembre de 2009 